\title{
Are Internal, Death-Promoting Mechanisms Ever Adaptive?
}

\author{
John W Pepper ${ }^{1,2}$, Deborah E Shelton ${ }^{1}$, Armin Rashidi ${ }^{1}$ and Pierre M Durand ${ }^{1,3 *}$ \\ ${ }^{1}$ Department of Ecology and Evolutionary Biology, University of Arizona, Tucson, USA \\ ${ }^{2}$ National Cancer Institute, Bethesda, Maryland, USA \\ ${ }^{3}$ Department of Molecular Medicine and Haematology, University of the Witwatersrand, Johannesburg, South Africa
}

\begin{abstract}
Natural selection acts primarily on organisms, and the existence of evolved, active, internal mechanisms that cause organismal death would seem paradoxical. However, there is substantial evidence that internal death promoting mechanisms exist and are taxonomically widespread. Where these are argued to be 'programmed organismal death' (POD), they require evolutionary explanations. Any such explanation must draw on our understanding of fitness trade-offs and multiple levels of selection in evolution. This review includes two main categories of putative POD: senescence in multicellular-organisms, and programmed cell death in unicellular organisms. The evidence for POD as a genetically controlled phenotype is strong for semelparous and significant but more controversial for iteroparous plants and animals. In multicellular organisms the program frequently (although not always) appears to be the result of fitness trade-offs. Here the death phenotype itself is not adaptive but the fitness related program most likely is. However, in some cases of behavioral suicide, particularly in insects, there are distinct advantages to kin and group level benefits may play a role. In unicells, programmed death is ubiquitous and POD often provides benefits to others. While benefits do not equate with adaptations, they are consistent with it. Here, death may be adaptive at a level other than the individual cell. In other instances of POD in unicells the phenotype (eg autophagy) can be explained as pleiotropy. The overall picture of POD as a natural phenomenon is still emerging, and continued work on diverse lines of evidence is necessary to complete our evolutionary understanding of this apparent paradox. While some questions remain, we conclude that POD is most likely, in some circumstances at least, adaptive.
\end{abstract}

Keywords: Programmed death; Adaptation; Unicellular; Organismal

\section{Introduction}

The idea that self-inflicted organismal death could be adaptive sounds, at face value, absurd. An adaptation is a trait that is suitable (apt) for the current circumstances or environmental challenges, and archetypal examples include traits that promote survival. Natural selection is the mechanism that produces adaptations. In describing natural selection, Darwin (1859) emphasized the struggle for survival: "Two canine animals in a time of dearth may be truly said to struggle with each other which shall get food and live [1]. But a plant on the edge of a desert is said to struggle for life against the drought....... How could an inherited trait that promotes death, rather than survival, possibly be adaptive?

Four categories encompass the major possible evolutionary explanations for the cause of death of an organism (Table 1). First, death (or an increased probability of death) could inevitably occur despite the efforts or traits of the organism. Second, internal mechanisms that promote death could exist in spite of selective pressure against them. Third, death could occur as a side-effect of a mechanism within the organism that has another function or benefit. Fourth, death could occur because of a mechanism within the organism that evolved explicitly to cause death. This fourth category is the only one in which the mechanism promoting death is an adaptation for promoting death, and cases in this category can only be explained by selection at a hierarchical level other than the organism.

In all categories except the first, we can reasonably expect to see active mechanisms within an organism that promote death. This review was motivated by the observation that diverse organisms apparently have such active, internal death-promoting mechanisms and by the subtle and difficult conceptual issues that understanding the evolution of this kind of trait raises. We use the term programmed organismal death (POD) to refer to organismal death that results directly from an active process that is internally controlled and regulated by the organism (although it may be triggered as a response to an external cue). Several terms from our definition require further explanation.
There are multiple concepts of what constitutes an individual organism for a particular taxon, or a particular biological question [2]. Here, we follow Gould and Lloyd (1999) in using "organism" in the conventional sense to refer to the discrete body of a highly integrated creature [3]. Thus, our idea of POD entails only that the organism in question be a discrete, highly integrated cell or multicellular body. The high integration and functionality that are characteristic of "organisms" (in this sense) are typically, and rightly, understood as a product of organism-level natural selection. However, it is important to note that identifying something as an "organism" in this sense does not imply that the organism level is the only level at which an effective selective process has been occurring or that organism-level selection is the primary cause of all the traits of the organism. For example, we speak of each bacterium within a biofilm as an "organism" (and speak about the active, regulated death of a bacterium as POD) without intending to automatically imply anything about the relative strength of cell-level and biofilm-level selection. Therefore in these and other instances where the cell is the organism (unicellular life forms) the terms POD and PCD (programmed cell death) are used synonymously.

By "death that results directly" and by "internally controlled" we intend to eliminate cases such as predation of an individual due to the "programmed" expression of a sexual ornament as well as cases in which parasites promote the death of a host by changing their behavior. In essence, we consider cases of apparently self-inflicted organismal death.

*Corresponding author: Pierre M Durand, Department of Ecology and Evolutionary Biology, University of Arizona, Tucson, USA, E-mail: pierre.durand@wits.ac.za

Received March 26, 2013; Accepted July 08, 2013; Published July 18, 2013

Citation: Pepper JW, Shelton DE, Rashidi A, Durand PM (2013) Are Internal, Death-Promoting Mechanisms Ever Adaptive? J Phylogen Evolution Biol 1: 113 doi:10.4172/2329-9002.1000113

Copyright: () 2013 Pepper JW, et al. This is an open-access article distributed under the terms of the Creative Commons Attribution License, which permits unrestricted use, distribution, and reproduction in any medium, provided the original author and source are credited. 


\begin{tabular}{|c|c|c|c|c|c|c|}
\hline & \multicolumn{4}{|c|}{ Mechanisms that promote death are: } & \multirow[b]{2}{*}{ Role of selection } & \multirow[b]{2}{*}{ Potential examples } \\
\hline & internal & controlled & $\begin{array}{l}\text { beneficial } \\
\text { overall }\end{array}$ & $\begin{array}{l}\text { beneficial by virtue of } \\
\text { promoting death }\end{array}$ & & \\
\hline Unavoidable death & possible & no & no & No & Selection for survival, not death & $\begin{array}{l}\text { Non-programmed forms like } \\
\text { necrosis }\end{array}$ \\
\hline Maladaptation & yes & possible, though not likely & no & No & Selection for survival, not death & $\begin{array}{l}\text { Senescence via mutation } \\
\text { accumulation }\end{array}$ \\
\hline By-product death & yes & yes & yes & No & $\begin{array}{l}\text { Selection at the organismal level } \\
\text { for mechanisms that produce } \\
\text { death as byproduct }\end{array}$ & $\begin{array}{l}\text { Regulation of allocation to } \\
\text { reproduction (fitness trade- } \\
\text { offs); autophagy }\end{array}$ \\
\hline Selected-for death & yes & yes & yes & Yes & $\begin{array}{l}\text { Selection at a level other than the } \\
\text { organismal level }\end{array}$ & $\begin{array}{l}\text { Programmed death in } \\
\text { unicellular organisms; } \\
\text { behavioral suicide in insects }\end{array}$ \\
\hline
\end{tabular}

Table 1: Evolutionary explanations for programmed death.

\begin{tabular}{|c|c|c|}
\hline Type of evidence and examples & Interpretation & Relevant references for interpretation of evidence \\
\hline $\begin{array}{l}\text { I. Internal vs. external causes of death } \\
-\quad \text { Mechanisms that promote death are genetically-based } \\
-\quad \text { Protein synthesis is needed for death to occur } \\
\text { - } \quad \text { Life span can be extended by manipulations (selective } \\
\text { breeding, prevention of reproduction, etc) }\end{array}$ & $\begin{array}{l}\text { Evidence against the "unavoidable death" } \\
\text { category of explanation. }\end{array}$ & {$[15-21]$} \\
\hline $\begin{array}{l}\text { II. Form of the mechanisms that promote death } \\
\text { Organization or complexity of molecular-genetic } \\
\text { pathways leading to death }\end{array}$ & $\begin{array}{l}\text { High complexity or organization of pathways } \\
\text { leading to an outcome is generally thought to } \\
\text { indicate that the outcome has been selected } \\
\text { for, though the issue is an active area of } \\
\text { current work. }\end{array}$ & [22-25] \\
\hline $\begin{array}{l}\text { III. Phylogenetic patterns } \\
\text { - Phylogenetic conservation of death mechanisms } \\
\text { - Convergence on similar death phenotypes }\end{array}$ & $\begin{array}{l}\text { Reduced variation (compared to expectation } \\
\text { from drift) as well as convergence is often } \\
\text { indications of selection. }\end{array}$ & [26-28] \\
\hline $\begin{array}{cl}\text { IV. Benefits of death } \\
-\quad \text { Benefit to offspring } \\
\text { - } \quad \text { Benefit to other kin } \\
\text { Benefits to the population }\end{array}$ & $\begin{array}{l}\text { For organismal death itself to be adaptive, it } \\
\text { must confer fitness benefits at a hierarchical } \\
\text { level other than the organism. }\end{array}$ & {$[17,29-32]$} \\
\hline
\end{tabular}

Table 2: The evidence relevant to evolutionary explanations of POD.

We consider "active" and "internally controlled and regulated" as sufficient descriptors of "programmed", although we recognize that this view of the meaning of "programmed" is not ubiquitous [4,5]. We use the word "program" to indicate that the inherited information of a cell can direct responses to the environment; the analogy with computer programs is imperfect, but helpful [6]. Observing that death is "programmed" in this sense simply eliminates the first category of explanations (unavoidable death); further evidence is required to discriminate among the remaining possibilities. Particular aspects of the "programmatic" nature of death may be evidence for or against some of the remaining categories, as summarized in Table 2 .

The final term that should be clarified at the outset is "adaptation", as our central concern is the question of whether death-causing mechanisms are adaptive in some cases. We follow Reeve and Sherman (1993) in defining an adaptation as "a phenotypic variant that results in the highest fitness among a specified set of variants in a given environment" [7]. It is a feature that is apt for the current circumstances, and current utility relative to some field of potential variants is the only criterion. This definition contrasts with others who require various versions of historical criteria to define an adaptation [8-10]. For our current purposes, the distinction is not critical. It is straightforward for those readers who understand "adaptation" to entail historical criteria to apply our summaries of evidence for POD to their own interpretation of "adaptation", though sufficient evidence to evaluate historical criteria is lacking in many, if not all, cases of putative POD. Ideally, sufficient evidence of adaptation occurs when the putative selective pressure for the phenotype is removed and the trait disappears over time. Some of us and others have acknowledged this [11]; although such an overly stringent criterion is likely impractical for evaluating POD in most organisms including unicells. Controls for such experiments may be technically impossible. Furthermore, failure for a trait to disappear after eliminating putative environmental pressures is also not the final word on the matter and does not exclude conflating phenomena like phenotypic integration, pleiotropy, modularity and weak selection.

Importantly, an affirmative answer to the question of whether a particular feature appears to be an adaptation (sensu [7]) can leave open the question of what it is an adaptation for [12]. Thus, when considering aspects of mechanisms that promote death, some features may simply suggest that POD (i.e., the mechanisms that lead to death) is an adaptation, whereas other features may suggest that POD is an adaptation for a particular function or outcome (e.g. death, regulation of energy allocation). Note again that if death is the function of POD (i.e., if POD is an adaptation for promoting death), then POD must be selected for at a level other than the organism level. Some authors have proposed functional hypotheses for the origin and maintenance of POD without rigorously considering the implied selection process [13]. Others cling dogmatically to the primacy of organism-level selection, even in the face of contradictory evidence [14]. Putative cases of POD (as a natural phenomenon, independent of evolutionary explanations) range from those that are solidly supported by empirical evidence to those that are merely suggested and sometimes controversial. To help establish the adaptive function (or lack thereof) of each putative case of POD, we explicitly consider that levels of selection may have shaped the traits in question.

Justifications of the evidence used to support claims that a particular trait is an adaptation (or is an adaptation for a particular function) are controversial [12]. In-depth treatment of particular lines of evidence or particular cases is beyond the scope of this review. Table 2 summarizes 
the lines of evidence that we consider with respect to POD and provides references that discuss the subtleties of some types of evidence for selection or adaptation.

This review includes two main categories of putative POD: senescence in macro-organisms and programmed cell death in unicellular microorganisms. Additionally, we briefly consider behavioral-mediated death in macro-organisms. We summarize various forms of evidence (Table 2) that are relevant to discriminating between the categories of death explanations (Table 1). How much evidence is sufficient to definitively assign an example to one of the categories in Table 1 is not straightforward. We generally leave this task to more detailed studies of particular cases, though we do point out categories of cases for which the bulk of the evidence so far points to a particular kind of explanation. Although there is also evidence for senescence of microbial lineages, in the form of loss of replicative potential, we restrict this review to organismal death and exclude reproductive senescence of lineages.

\section{Organismal Senescence as Programmed Death}

Clearly it can be adaptive for a large organism to cause the senescence of specific organs or structures, such as leaves on a deciduous plant. Whole-organism senescence leading to death is more puzzling, and explaining it has been a long-standing challenge. If a large organism can build itself from a single cell, why can it not maintain itself once built? Or can organismal death actually be adaptive in some cases, in the sense of increasing Darwinian fitness?

\section{Evidence from Semelparous organisms}

The strongest appearance of POD in organismal senescence is found in semelparous species, which reproduce only once during the life cycle. A common pattern in these species is that individuals appear healthy up to the time of reproduction, then decline rapidly and dramatically afterward. Mortality in these cases is often $100 \%$, with no obvious environmental cause. In some species, there is considerable empirical evidence for a tightly regulated "death program", or organismal initiation and control of the process leading to death.

Semelparity is common in long-lived plants, occurring in representatives of at least 20 different families [34]. In most cases, the proximate mechanisms of death are unknown, but there is evidence in some species for an internally generated "senescence signal", which may be a hormone [35].

Semelparous animals show a similar pattern. Among vertebrates, the best studied examples of rapid senescence and death following semelparous reproduction are in fishes and marsupial mammals. Anadromous Pacific salmon (Oncorhynchus spp.), and catadromous eels (Anguilla spp.) and lampreys (Petromyzontidae) die shortly after spawning. Males of several small marsupials die shortly after mating (reviewed in [36]). Remarkably, the proximate molecular mechanisms of decline and death in all these distantly related vertebrates seem to be similar, with corticosteroid stress hormones playing the central role [37].

Among invertebrates, cases of death following semelparous reproduction that clearly seem to be coded into the genome (and thus "programmed") include the many insects in which adults entirely lack mouthparts or are otherwise incapable of feeding [38]. In some cephalopod molluscs, rapid senescence and death follow spawning (squids) or brooding (octopuses). For example, in Octopus hummelincki, brooding females alter and reduce feeding behavior and die shortly after their eggs hatch. These traits are influenced by endocrine secretions from the optic gland $[39,40]$.
In both plants and animals, life span can be is extended by experimental manipulations of physiology and/or reproduction, indicating that senescence is not the inevitable outcome of physical constraints. For example, lifespan of semelparous annual plants can often be artificially extended by removing reproductive structures [35]. Optic gland removal in $\mathrm{O}$. hummelincki causes cessation of brooding, reinstates normal feeding behavior, and extends life [39]. In fishes, removal of the gonads (Pacific salmon, lampreys) or of the pituitary gland (lampreys) and prevention of mating (eels) can substantially increase life span [41-43]. Similarly in small marsupials, castration [44] or prevention of mating [45] can increase male life span up to that of females. These experiments indicate that rapid senescence and death following reproduction in at least some semelparous animals are genetically "programmed" and internally controlled.

\section{Evidence from Iteroparous organisms}

Iteroparous organisms have multiple reproductive episodes during the life cycle, as opposed to a solitary event. In these species, senescence leading to death is less abrupt and dramatic, but is ubiquitous nonetheless. Although data are difficult to collect, a high rate of death due to senescence in iteroparous species has been documented for some species even in the wild [46]. General explanations for organismal senescence are varied and contentious, and the idea that iteroparous senescence is "programmed" is not the majority view [5]. However, there is substantial evidence for genetic control of senescence in some iteroparous animals, indicating that senescence is at least sometimes "programmed" (in the inclusive sense) and highlighting the question of the relationship between aging "programs" and selection. For example, in Drosophila melanogaster, selective breeding and other studies demonstrated a genetic, heritable component to senescence [47-49]. In humans, geriatric diseases measured in some family members can predict life span in other family members [50]. In several model organisms, the specific genes influencing life span have been identified and there are now numerous examples where a molecular network promotes fitness early in life only to result in senescence and decreased fitness later (reviewed in [19]). These are the genetic mechanisms for the Anatagonistic Pleiotropy (AP) hypothesis discussed below. Many of the explanations can be attributed to the concept of disposable soma [51,52], which proposes a trade-off between investment in maintenance and repair versus investment in reproduction [53].

As one well-studied example, the IGF-1 signaling pathway is involved in regulating life span in several model organisms, including flies, nematodes, and rodents [54]. Several loci interact in what the authors term a "survival pathway". The authors suggest that this pathway is activated to "survive unfavorable conditions in an effort to reproduce at a later time" (p. R664). The obvious implication is that the same survival pathway is deactivated under other conditions in which survival for later reproduction is less advantageous. Variants of the IGF-1 receptor homolog (daf 2) in the model organism C. elegans have produced empirical support for these arguments [55]. Recessive mutations in this gene significantly increased organismal lifespan. There are a number of other genes including those coding for steroids, apoptosis proteins and transcription factors that strongly support AP at the molecular level (for a review see [56]).

\section{Evolutionary theory for organismal senescence}

Most evolutionary explanations of organismal senescence are based on individual selection or selective neutrality, and interpret senescence as a byproduct rather than an adaptation selected for its own sake. Both the AP (discussed above) and the mutation accumulation hypotheses, 
two of the widely accepted explanations, propose mechanisms with negative effects that manifest late in life.

These hypotheses are distinguished by the early effects of genes and mutations. AP refers to traits with early positive effects that trade off against later negative effects $[57,58]$ while mutation accumulation refers specifically to costly mutations with no fitness effect early in life $[59,60]$. Both of these hypotheses are based on the proposition that the force of natural selection declines with age, as the potential for further reproduction declines either abruptly or gradually [61]. The existence of genetic heritability in complex, functional pathways suggests that senescence is internally initiated and controlled by the organism. AP, therefore, meets our criteria for being "programmed" although in mutation accumulation a program per se seems unlikely. The failure of selection to maximize life span raises the question of why evolution would favor organisms that forego the potential advantage of longer reproductive lives.

The hypotheses described above are not mutually exclusive and are sometimes grouped as the "evolutionary" or "life history" theories of senescence $[38,61]$. There is a large body of literature, particularly for semelparous organisms, that is consistent with their predictions. In many semelparous organisms, the adaptive function of the nominal 'death program' is apparently to increase reproduction, with organismal death resulting as an incidental side-effect (making organismal senescence an example of "by-product death", Table 1). In vertebrates, for example, the high levels of free corticosteroids that trigger rapid senescence and death also allow tissue protein to be consumed as an energy source during a brief and intensely competitive breeding season [62,63]. In Pacific salmon [64] and the marsupial Antechinus stuartii [36], the ability to exploit tissue protein as an energy reserve may increase reproductive success. In Octopus, the behavioral effects of optic gland secretion are likely to have an impact on hatching success, as time spent feeding is time not spent on brood care. In semelparous plants, a trade-off between survival and reproduction is supported by both experimental and comparative evidence. Various methods of preventing reproduction can extend life span [35], and reproductive effort is negatively correlated with life span across species [65].

The case for individual-based explanations of senescence is less clear for iteroparous organisms. Although some studies have supported life history theories of senescence, others have failed to provide clear support. For example, Williams (1957) predicted that "Low adult death rates should be associated with low rates of senescence, and high adult death rates with high rates of senescence" [57]. While this prediction has been empirically confirmed by some comparative studies of mammal populations $[66,67]$, there are a few interesting exceptions that are worth mentioning. A comparison of guppy populations found the opposite pattern [68]. In interpreting the latter results as compatible with AP, Reznick et al. appealed to a different prediction generated from a mathematical model [69]. However, this interpretation has been criticized as misinterpreting Abrams' work [70].

AP has also been tested in a long-running experiment using artificial selection for increased life span in Drosophila flies. After two years of selection, life span increased, while early fecundity declined, which corroborates the AP hypothesis [61]. After further selection however, life span continued to rise, while fecundity also rose at all ages, including early in life. While this result seems to contradict AP predictions it was instead interpreted by the authors as an experimental artifact [71]. Similarly, a recent study of Caenorhabditis elegans reported that selecting for early fecundity did not produce a cost in terms of longevity [72] while other studies designed to measure trade- offs between survival and reproduction have found no evidence for them $[73,74]$. This criticism is not conclusive, however, and should be explored further as "incorrect predictions and faulty tests" have plagued studies of trade-offs in general [75].

Any cases for which we accept organismal senescence as being "programmed" (either in the weaker sense of being "coded" somehow in the genes or in the stronger sense of resulting from apparently goaldirected, hierarchical cascades of molecular-genetic interactions) challenge us to explain the origin and maintenance of the "death program". AP and disposable soma hypotheses are widely accepted as the standard explanations for genetic programs that cause senescence in multicellular organisms [5]. However, there are some results (discussed above; see also [74]) that are in conflict with their predictions.

A common theme in all the hypotheses discussed above is that the organism is the primary unit of selection. In contrast, other authors have advanced alternative views for the adaptive value of POD in a multilevel selection framework. Among those authors that accept organismal death as programmed, many also support the hypothesis that death is adaptive, generally at a level of function other than the individual organism $[17,19,30,70,74,76-78]$.

Supra-individual functions have occasionally been proposed for POD, although these suggestions sometimes lack both a rigorous theoretical framework and direct experimental evidence. The spectacular post-spawning mortality of Pacific salmon, for example, has been hypothesized to benefit offspring by enriching stream nutrient levels $[19,79]$. However, a benefit to offspring of the population at large, rather than of the dying individual specifically, would only be favored by a process of selection among populations, which has not been either documented or explicitly proposed. In other cases, benefits are apparently directed specifically to offspring of the dying individual, and this type of death could be favored by individual selection for maximizing successful reproduction. For example, in the neotropical rainforest tree Tachigalia versicolor, death of the parent tree is thought to open a light gap in the canopy that specifically benefits offspring of the dying tree $[38,80]$.

It has been proposed that POD through organismal senescence is favored by kin selection [77,78], by group selection [19,70], or by selection among populations, with a more detailed model of the selection process than had accompanied early suggestions of population-level function [81].

\section{Behavioral Suicide as Programmed Death in Animals}

Decades ago, folklore held that arctic lemmings commit suicide in order to control population density for the good of the species. While this belief was widely held due to erroneous popular accounts, it was not empirically supported [82]. However, other observations of organismal suicide have been carefully researched and documented. Pea aphids (Acyrthosiphon pisum) that are parasitized by the Braconid wasp Aphidius ervi drop from the host plant, causing their own death. These insects live in groups of close kin, and their death prevents their body from producing parasites that would then attack their siblings. Death therefore increases the individual's inclusive fitness, or equivalently, increases the fitness of the kin group [83,84]. At the same time, pleiotropic incidental mechanisms are also feasible. "Male self-sacrifice", or apparent male cooperation with female cannibalism, is part of male copulatory behavior in several spider species, and in some insects $[85,86]$. One study also reported that males of the spider Argiope aurantia spontaneously die when they copulate [87]. Extensive details of the physiological or molecular mechanisms leading to 
"spontaneous" death or of the neurological mechanisms underpinning death-promoting behavior in spiders have not been reported. In redback spiders, cannibalized males increase their paternity compared to non-cannibalized males, so it is thought that self-sacrifice evolved due to this reproductive advantage [88]. The fitness benefit provided by this behavior raises intriguing possibilities. Among eusocial insects, workers routinely sacrifice their lives to benefit the colony and their siblings. One familiar example occurs in honeybee workers, which commit suicide each time they sting invaders in defense of their hive [89]. Similarly, these workers altruistically commit suicide in ways that apparently function to prevent the spread of disease within the hive [90]. In these cases, there is little mystery concerning function or evolution. Kin selection, or equivalently, selection among colonies, is a powerful force shaping the evolution of eusocial insects [91].

\section{Programmed Death in Unicellular Organisms}

Programmed cell death (PCD) serves the interests of multicellular organisms in many ways. Because it increases the fitness of the organism, there is no mystery about the function of PCD in plants and animals. It seems paradoxical, however, in cases where the single cell is the entire organism, so that PCD, by definition, is also POD. This issue is complicated by multiple competing criteria for what entities constitute organisms versus parts of organisms. In some species ambiguity arises as to whether cells are organisms or parts of organisms [2]. The apparent paradox of unicellular POD is common. POD with its diverse phenotypic manifestations has been observed in four of the five eukaryote super-groups defined by Keeling et al [92], as well as in prokaryotes $[16,93]$ (also see Figure 1).

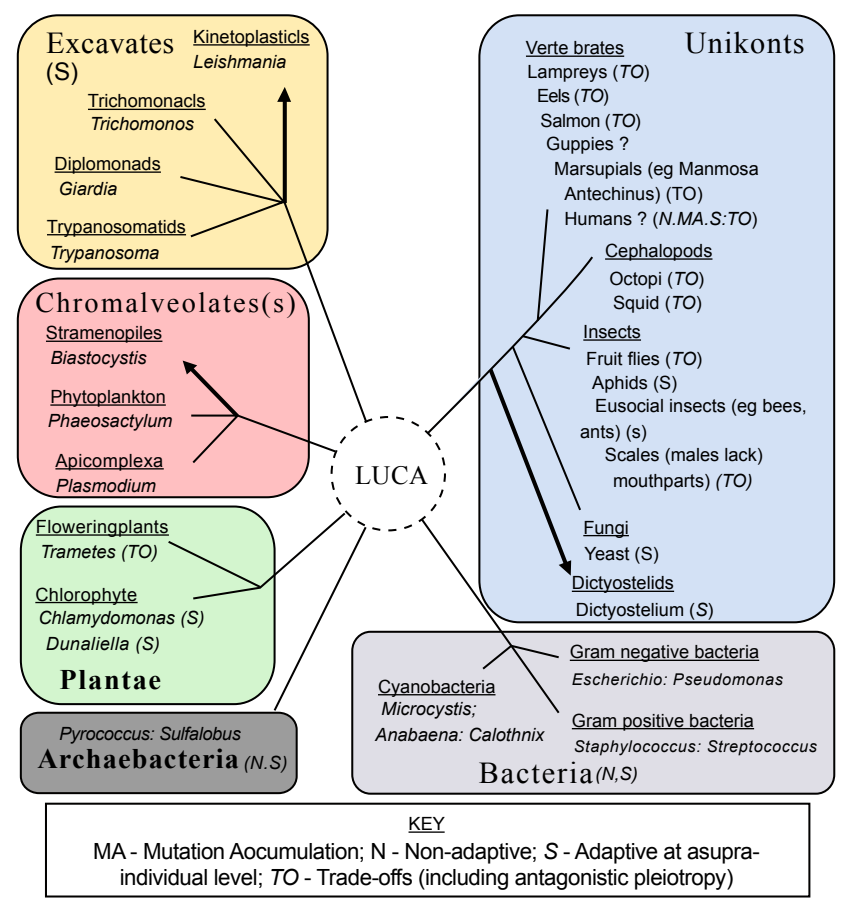

Figure 1: Programmed organismal death

A schematic representation of taxa discussed in the text. Organisms in the four eukaryote super-groups (Unikonts, Excavates, Chromalveolates and Plantae) are classified according to the "deep" eukaryote tree proposed by Keeling et al. (2005). For each taxon the proposed non-adaptive and/or adaptive explanations for POD are provided in parentheses (see key). The cases of convergent evolution identified in unicellular eukaryotes (see text) are indicated by bold arrows. LUCA = Last Universal Common Ancestor.

\section{Evidence for POD in unicells}

There is substantial evidence that cell death is often internally controlled and regulated in unicellular organisms, (Table 1 in [11]). The ancient and deeply conserved genetic and molecular pathways that cause cell death indicate that death-promoting mechanisms show less variability than would be expected for unavoidable or maladaptive death. For example, the caspase gene super-family is involved in cell death in both prokaryotes and eukaryotes, suggesting that it is functionally conserved and arose early in prokaryote evolution [20,94,95]. Potential convergence on the autophagic death phenotype also indicates that death-promoting mechanisms may have been selected for in unicells (though the function of the mechanisms may not be death per se in this example). The autophagic death phenotype and elements of its molecular pathway have been described in evolutionarily diverse, unrelated unicellular eukaryotes such as the stramenopiles [96], the kinetoplastids [97] and the social amoebae [98] (Figure 1). (Of course, one would need more evidence to rigorously establish that different mechanisms underpinning autophagy evolved independently and are maintained in different lineages by selective pressures stemming from similar environmental challenges.) Many bacteria undergo cell death mediated by hydrogen peroxide during stationary phase or in certain locations in a developing biofilm. Interestingly, gram-positive species produce hydrogen peroxide via the enzyme pyruvate oxidase [99] and references there, [16], while many gram-negative species generate hydrogen peroxide by the production of lysine oxidase [100]. The presence of (at least) two distinct means of triggering hydrogen peroxide production suggests convergent evolution, and thus suggests a widespread selective force favoring PCD in bacteria. The independent emergence of autophagic death in several eukaryotes and of hydrogen peroxide-mediated death in several prokaryotes is strongly supportive of POD as an adaptation although whether this is due to selection at levels other than the organism is debatable [11].

Examples of POD in model unicellular eukaryotes include yeast Saccharomyces cerevisiae [18,101-103], chlorophytes Chlamydomonas reinhardtii [29] and Dunaliella salina [33] and several protist parasites including Plasmodium [104], Trichomonas [105], Leishmania [106], and Trypanosoma $[107,108]$. Evidence of POD has also been documented in numerous non-model species including several eukaryotic phytoplanktons [15] (summarized in Table 1 in [11]). POD is also widespread among prokaryotes, where it occurs through a diversity of non-homologous pathways [16]. POD has been demonstrated in many bacterial species [100-110] including colonial cyanobacteria like Microcystis aeruginosa [111,112] and Microcystis flos-aquae [113].

\section{Function and selection of POD in unicells}

We must ask of unicellular organisms the same question we asked about multicellular organisms: Is death the function of POD, or merely a side effect? Multicellular organisms undergoing POD typically do leave offspring, so active death that is a byproduct of mechanisms "designed" to regulate investment in reproduction is a viable (and often supported) hypothesis for multicellular POD. However, unicells undergoing POD do not leave any direct descendants. Thus, in unicells, POD (with the possible exception of autophagy) may involve adaptation through function, and selection, at levels other than the individual organism. There is experimental evidence of benefits at levels other than the organism in bacteria and some eukaryotes, as well as a range of possible functions. Proposals include levels both below (genetic element) and above (group) that of the individual cell. Below we review evidence for benefits at levels other than the individual, as well as proposed functions and levels of selection for POD in unicells. 


\section{Evidence for benefits of POD in unicells}

There is direct experimental evidence for higher-level benefits associated with POD in unicells. In bacterial species, several studies have compared group-level function in POD-positive versus PODnegative strains. Mai-Prochnow et al. showed that biofilms formed by a Pseudoalteromonas tunicata mutant defective in an autolysis pathway released far fewer propagules than the wild type [114]. The cells that were released from mutant biofilms were in a poor metabolic state, suggesting that autolysis may provide dispersing cells with nutrients as well as a means to escape the interior of the biofilm. The formation of healthy, physically stable biofilms in general is impaired in PODnegative mutants of Pseudomonas aeruginosa [115], Staphylococcus aureus [32,116], and Escherichia coli [117]. Furthermore, PODnegative mutants of Myxococcus xanthus are defective in fruiting body formation [118]. In E. coli, a small subpopulation of a clonal group undergoes autolysis, releasing anti-competitor toxins. In spatially structured environments, this strategy grants the clone as a whole enhanced competitive ability $[119,120]$. Another elegant study in E. coli allowed two strains, one capable of programmed death the other not, to compete against each other in the same environment [17]. On infection by a phage, the strain capable of programmed death outcompeted the non-POD strain, indicating that there is a fitness benefit at the clonal level despite the absolute fitness cost to the individual. This occurred even though individuals in the population were not closely related. These studies provide solid experimental evidence for grouplevel benefits of POD among bacteria. Evidence for benefits above the cell-level can be found in the eukaryote Dictyostelium mucoroides [121] and the chlorophytes Chlamydomonas reinhardtii [29] and Dunaliella salina [33]. The D. mucoroides life cycle resembles that of $M$. xanthus, and POD-negative strains are also unable to produce fruiting bodies. In C. reinhardtii, it has been shown that the mode of death impacts others in the population and that POD materials confer a fitness advantage on others while non-programmed death is harmful. Similarly, POD in D. salina allows others in the population to grow more vigorously and the mechanism was shown to be via dissolved organic materials (DOM) released during programmed death [33]. Interestingly, in this case a co-habiting archaeon could also utilize the liberated DOM. The significance of this in terms of the benefits being adaptive versus nonadaptive is uncertain.

\section{Proposed Levels of Selection}

\section{Kin / group selection}

As discussed above, there is considerable experimental evidence for fitness advantages from POD to clonal kin groups of cells of species usually considered to be 'unicellular'. These fitness advantages may represent a significant source of selection pressure. As one well-studied example, clonal growth of yeast colonies creates opportunities for strong kin selection and evolution of group-beneficial altruistic traits [122]. PCD could serve at least two altruistic purposes in this context. By dying, a cell may spare nutrient resources for its neighboring kin group. Cell death could also release useful substances that can be used by the cell's clone-mates $[29,30,33,123]$. In the model green alga Chlamydomonas reinhardtii, the benefit appears more active. In a direct POD vs nonPOD fitness comparison, cells dying by POD enhance the fitness of relatives [29]. Furthermore, the fitness advantages of C. reinhardtii are species specific and cellular lysate following POD inhibits the growth of other Chlamydomonas species (manuscript in review).

Unicellular parasites are expected to be subject to strong selection among groups that share a host during a stage of the life cycle, and tend to have a shared fate as a result $[124,125]$. Consistent with this theoretical expectation, markers of POD have been described in many phylogenetically distant unicellular parasites. Furthermore, as in other unicells POD is active and requires protein synthesis. For example in Plasmodium, the inhibitory action of cycloheximide indicates that POD requires transcription and protein synthesis [104]. A direct group vs group comparison to assess group level effects of POD yielded unexpected results in Leishmania major [126]. Surprisingly, an inoculum containing apoptotic (cells dying by POD) organisms was more virulent than one without apoptotic organisms despite the inoculum containing apoptotic organisms having fewer viable parasites. The implication is that the apoptotic cells release substances that enhance the growth of others in the group.

Some groups of bacterial cells are functionally organized. In filamentous cyanobacteria such as Calothrix and Trichodesmium, poor conditions induce POD in some cells $[127,128]$. Because the filament often breaks up as a result, the function of POD in this system could be filament dispersal in response to unfavorable environmental conditions.

Biofilms are another common form of functional organization in groups of unicells. The lethal effect of chromosomal toxin-antitoxin systems may be mediated by extracellular signals [129], and these signals are central to biofilm development in Escherichia coli [117]. Homologous toxin-antitoxin systems have been identified in other gram-negative bacteria, gram-positive bacteria [130], and archaea [131]. A homolog to a phage holin-antiholin system on the chromosome of Staphylococcus aureus [132] suggests that these genes may serve a novel function at or above the level of individual cells. Homologs of this system are widespread among true bacteria and archaea [133].

In eukaryotes as well, the distinction between unicellular and multicellular is not always completely clear. For example, the social amoeba, Dictyostelium discoidium, is unicellular during part of its life cycle, but upon starvation, cells aggregate and develop into a multicellular motile slug, then fruiting body. Stalk cell death is programmed and is characterized by some classic features of POD [134]. The dead stalk cells function to support the spore head (which are often clonal relatives of stalk cells), presumably contributing to the spores' dispersal. Therefore, the stalk cell death program appears to be the result of selection among multicellular aggregates. A different and less clearly functional death program has also been described in nonaggregated D. discodium [135].

\section{Genic selection}

The reproductive interests of genetic elements can differ from those of the organism carrying them. It is well established that gene-level selection can generate traits that are detrimental to individual fitness, while benefitting smaller genetic entities within them [136]. Indeed, genetic elements have been closely studied that routinely increase their inclusive fitness by killing their host [137]. In some cases, this peculiar form of selection may explain the function and evolution of genes for unicell POD. When a cell has low chances for reproduction, POD and the transfer of genes from the dying cell to a new host can save the genes. This process may be associated with occurrence of new mutations in the transferred genes and their improved ability to survive in the new host. This mechanism has been suggested to occur in $S$. cerevisiae [138] although the author allows that, "this hypothesis lacks direct experimental support".

In prokaryotes, conjugative plasmids often encode for the simultaneous production of long-lived toxins and short-lived antitoxins [21]. When these are present together, the toxin is harmless to the host. 
However, if one daughter cell is cured of the plasmid, it will inherit toxic cytoplasm without a source of antitoxin and will die. While this is easily explained as a 'selfish' adaptation on the part of the plasmid, chromosomally-encoded toxin-antitoxin systems probably do not function in gene-level competition [139]. A similar puzzle arises in the case of holin-antiholin systems, which are encoded by bacteriophages and control the timing of host cell lysis and the dispersal of virions [140]. Chromosomally-encoded homologs are biochemically distinct from toxin-antitoxin systems, but also result in cell death (reviewed in [16]).

Plasmids and bacteriophages may induce cell death in the host (or non-host daughter) cell. Whether or not this is considered an example of POD, of course, hinges on whether or not selfish genetic elements are considered part of the organismal genome. The benefits in this case are straightforward and focused on the level of the selfish genetic element. This simple case may become more complicated when multiple levels of function and selection are involved. For example, in the case of phagemediated cell death in Pseudomonas aeruginosa, the lethal action of the lytic phage appears to confer a 'group-level' (or biofilm-level) benefit by allowing the release of a subpopulation of well-nourished disperser cells [114].

\section{Population-level selection}

The idea of selection among multi-generation populations or 'demes' predates more recent theory on selection among temporary 'trait-groups' [141]. Some authors have proposed that capacity for POD can offer long-term advantages to a species or other population. Because cellular damage is an important predictor of POD in yeast, it was suggested that one function of death is to remove cells with physical $[142]$ or genetic $[31,131,143]$ damage from the population. Elimination of mutated cells could help the population maintain its genetic stability. In "adaptive regrowth", when the majority of cells in a stressed colony die by POD, a mutant, well-adapted minority arises and rescues the population, aided by the resources provided by lysed cells $[30,101]$.

\section{Conceptual Issues and Future Considerations}

Given the definitions and usage of terms laid out at the start of this review, an answer to the title question as to whether internal, deathpromoting mechanisms can ever be adaptive, the answer must be a qualified 'yes'. The evidence for programmed organismal death (POD) as a natural phenomenon is compelling for semelparous plants and animals, and substantial but more controversial for iteroparous macroorganisms. In these cases the 'program' (used in the inclusive sense here) appears to result largely from the constraints of physiological trade-offs as encompassed by, for example, antagonistic pleiotropy, notwithstanding some conflicting evidence. Explaining the evolution of death-promoting mechanisms often draws on lines of evidence that can be difficult or subtle to interpret (Table 2). However, if the death phenotype itself is adaptive, then selection at levels other than the individual organism is implicated. In cases where the death promoting phenotype is a by-product, then a complete explanation should ideally include both the adaptive function (purpose) of the mechanisms underpinning death as well as the reasons why selection has failed to achieve the function (purpose) without also promoting death. Death is a severe and absolute fitness cost. Except where there are physiological constraints as in antagonistic pleiotropy in multicellular organisms, the cases that seem to present the most pressing challenges are the welldocumented and diverse examples of POD in unicellular organisms. One intuitively appealing solution to this paradox is that the unit of adaptation for these traits in the unicellular world is a larger collective. Indeed the idea has arisen repeatedly that what we are accustomed to calling unicellular species are in some cases, and by some criteria, actually multicellular or at least colonial groups. Such a case can be made for eukaryotes such as social amoebae and other eukaryotes where group selection may play a significant role. In addition, for prokaryotes that form functionally important aggregates such as filaments and biofilms $[130,144]$ the collective or group can sometimes be more relevant as a level of selection.

A valid criticism of this argument is that most of the evidence for POD as an adaptation in unicells rests, for the moment anyway, on the findings that POD can provide benefits to others. Nevertheless, group level advantages have sometimes been observed and POD in a unicellular colony may well provide inherited group level benefits due to population structures and genetic relationships that can be acted on by natural selection. However, as stated earlier benefits support but do not prove adaptation. For example, death in Pacific salmon may provide nutrients to developing embryos; but this form of POD can be explained by organism level fitness trade-offs.

The two classes of explanation that may have the widest applicability are those involving organismal adaptation under constraining tradeoffs (especially for macro-organisms), and those involving adaptation at higher levels of organization than the presumptive organism (especially for micro-organisms). In the latter cases, not only is a higher level of selection implied, but this selection must be strong enough to generate the extreme form of altruism represented by POD. Further progress on understanding the evolution of POD will depend on advancing diverse lines of evidence (Table 2) as well as considering carefully the effects of selection under constraining trade-offs and at multiple hierarchical levels. Such research is needed to fully reconcile the view that "every single organic being around us may be said to be striving to the utmost to increase in numbers" [1] with the observation that organisms can evolve mechanisms that promote their own death.

\section{Acknowledgments} Herron.

We gratefully acknowledge contributions by William W. Driscoll and Matthew

\section{References}

1. Darwin C (1859) The Origin of Species by Means of Natural Selection or the Preservation of Favoured Races in the Struggle for Life. (First Edition) London: John Murray.

2. Pepper JW, Herron MD (2008) Does biology need an organism concept? Biol Rev Camb Philos Soc 83: 621-627.

3. Gould SJ, Lloyd EA (1999) Individuality and adaptation across levels of selection: how shall we name and generalize the unit of Darwinism? Proc Nat Acad Sci U S A 96: 11904-11909.

4. Austad SN (2004) Rebuttal to Bredesen: 'The non-existent aging program: how does it work?'. Aging Cell 3: 253-254.

5. Kirkwood TB, Melov S (2011) On the programmed/non-programmed nature of ageing within the life history. Curr Biol 21: R701-707.

6. Johnson BR, Lam SK (2010) Self-organization, Natural Selection, and Evolution: Cellular Hardware and Genetic Software. BioScience 60: 879-885.

7. Reeve HK, Sherman PW (1993) Adaptation and the goals of evolutionary research. Quarterly Review of Biology 68: 1-32.

8. Fessler DM, Navarrete CD, Hopkins W, Izard MK (2005) Examining the termina investment hypothesis in humans and chimpanzees: associations among maternal age, parity, and birth weight. Am J Phys Anthropol 127: 95-104.

9. Gould SJ, Vrba ES (1982) Exaptation-a missing term in the science of form Paleobiology 8: 4-15.

10. Sober E (1984) The nature of selection (Cambridge: MIT Press).

11. Nedelcu AM, Driscoll WW, Durand PM, Herron MD, Rashidi A (2011) On the paradigm of altruistic suicide in the unicellular world. Evolution 65: 3-20. 
12. Van Valen L (2009) How ubiquitous is adaptation? A critique of the epiphenomenist program. Biology \& Philosophy 24: 267-280.

13. Deponte M, Becker K (2004) Plasmodium falciparum--do killers commit suicide? Trends Parasitol 20: 165-169.

14. Atzmony D, Zahavi A, Nanjundiah V (1997) Altruistic behaviour in Dictyosteliumdiscoideum explained on the basis of individual selection. Current Science $72: 142-145$

15. Bidle KD, Falkowski PG (2004) Cell death in planktonic, photosynthetic microorganisms. Nat Rev Microbiol 2: 643-655

16. Rice KC, Bayles KW (2008) Molecular control of bacterial death and lysis. Microbiol Mol Biol Rev 72: 85-109, table of contents.

17. Refardt D, Bergmiller T, Kümmerli R (2013) Altruism can evolve when relatedness is low: evidence from bacteria committing suicide upon phage infection. Proc Biol Sci 280: 20123035.

18. Madeo F, Carmona-Gutierrez D, Ring J, Büttner S, Eisenberg T, et al. (2009) Caspase-dependent and caspase-independent cell death pathways in yeast. Biochem Biophys Res Commun 382: 227-231.

19. Longo VD, Mitteldorf J, Skulachev VP (2005) Programmed and altruistic ageing. Nat Rev Genet 6: 866-872.

20. Koonin EV, Aravind L (2002) Origin and evolution of eukaryotic apoptosis: the bacterial connection. Cell Death Differ 9: 394-404.

21. Jensen RB, Gerdes K (1995) Programmed cell death in bacteria: proteic plasmid stabilization systems. Mol Microbiol 17: 205-210.

22. Bredesen DE (2004) The non-existent aging program: how does it work? Aging cell 3: $255-259$

23. Knight CG, Pinney JW (2009) Making the right connections: biological networks in the light of evolution. Bioessays 31: 1080-1090.

24. Le Nagard H, Chao L, Tenaillon O (2011) The emergence of complexity and restricted pleiotropy in adapting networks. BMC Evol Biol 11: 326.

25. MacDougall-Shackleton SA (2011) The levels of analysis revisited. Philos Trans R Soc Lond B Biol Sci 366: 2076-2085.

26. Hansen TF (1997) Stabilizing Selection and the Comparative Analysis of Adaptation. Evolution 51: 1341-1351.

27. Leroi AM, Rose MR, Lauder GV (1994) What does the comparative method reveal about adaptation? American Naturalist 143: 381-402.

28. Losos JB (2011) Convergence, adaptation, and constraint. Evolution 65: $1827-$ 1840.

29. Durand PM, Rashidi A, Michod RE (2011) How an organism dies affects the fitness of its neighbors. Am Nat 177: 224-232.

30. Fabrizio P, Battistella L, Vardavas R, Gattazzo C, Liou LL, et al. (2004) Superoxide is a mediator of an altruistic aging program in Saccharomyces cerevisiae. J Cell Biol 166: 1055-1067.

31. Gomes DS, Pereira MD, Panek AD, Andrade LR, Eleutherio EC (2008) Apoptosis as a mechanism for removal of mutated cells of Saccharomyces cerevisiae: the role of Grx2 under cadmium exposure. Biochim Biophys Acta 1780: $160-166$.

32. Rice KC, Mann EE, Endres JL, Weiss EC, Cassat JE, et al. (2007) The cidA murein hydrolase regulator contributes to DNA release and biofilm development in Staphylococcus aureus. Proc Natl Acad Sci U S A 104: 8113-8118.

33. Orellana MV, Pang WL, Durand PM, Whitehead K, Baliga NS (2013) A role for programmed cell death in the microbial loop. PLoS One 8: e62595.

34. Young TP, Augspurger CK (1991) Ecology and evolution of long-lived semelparous plants. Trends Ecol Evol 6: 285-289.

35. Noodén LD, Guiamet JJ, John I (2004) Whole plant senescence. In Plant cel death processes Amsterdam: Elsevier, Inc: 227-244.

36. Cockburn A (1997) Living slow and dying young: senescence in marsupials. In Marsupial biology: recent research, new perspectives (ed. N. Saunders \& L. Hinds) Sydney: University of New South Wales Press: 163-171.

37. Stein-Behrens BA, Sapolsky RM (1992) Stress, glucocorticoids, and aging Aging (Milano) 4: 197-210.

38. Finch CE (1990) Longevity, senescence, and the genome. Chicago: University of Chicago Press.
39. Wodinsky J (1977) Hormonal inhibition of feeding and death in octopus: contro by optic gland secretion. Science 198: 948-951.

40. Rocha F, Guerra A, González AF (2001) A review of reproductive strategies in cephalopods. Biol Rev Camb Philos Soc 76: 291-304.

41. Robertson OH (1961) PROLONGATION OF THE LIFE SPAN OF KOKANEE SALMON (ONCORHYNCHUS NERKA KENNERLYI) BY CASTRATION BEFORE BEGINNING OF GONAD DEVELOPMENT. Proc Natl Acad Sci U S A 47: 609-621.

42. Larsen LO (1980) Physiology of adult lampreys, with special regard to natural starvation, reproduction, and death after spawning. Canadian Journal of Fisheries and Aquatic Sciences 37: 1762-1779.

43. Larsen LO (1985) The role of hormones in reproduction and death in lampreys and other species which reproduce once and die. In Current trends in comparative endocrinology (ed. B. Lofts \& W. N. Holmes) Hong Kong: Hong Kong University Press: 613-616.

44. Bradley AJ, McDonald IR, Lee AK (1976) Corticosteroid-binding globulin and mortality in a dasyurid marsupial. J Endocrinol 70: 323-324.

45. Wooley P (1966) Reproduction in Antechinus spp. and other dasyurid marsupials. Symposia of the Zoological Society of London 15: 281-294.

46. Nesse RM (1988) Life table tests of evolutionary theories of senescence. Exp Gerontol 23: 445-453.

47. Rose MR (1984) Laboratory evolution of postponed senescence in Drosophila melanogaster. Evolution 38: 1004-1010

48. Stearns SC, Ackermann M, Doebeli M, Kaiser M (2000) Experimental evolution of aging, growth, and reproduction in fruitflies. Proc Natl Acad Sci U S A 97 3309-3313.

49. Poirier L, Seroude L (2005) Genetic approaches to study aging in Drosophila melanogaster. Age (Dordr) 27: 165-182.

50. Kulminski AM, Arbeev KG, Culminskaya IV, Ukraintseva SV, Christensen K, et al. (2009) Health-related phenotypes and longevity in danish twins. J Gerontol A Biol Sci Med Sci 64: 1-8.

51. Kirkwood TB, Austad SN (2000) Why do we age? Nature 408: 233-238.

52. Ljubuncic P, Reznick AZ (2009) The evolutionary theories of aging revisited--a mini-review. Gerontology 55: 205-216.

53. Kirkwood TB (1977) Evolution of ageing. Nature 270: 301-304.

54. Narasimhan SD, Yen K, Tissenbaum HA (2009) Converging pathways in lifespan regulation. Curr Biol 19: R657-666.

55. Dorman JB, Albinder B, Shroyer T, Kenyon C (1995) The age-1 and daf-2 genes function in a common pathway to control the lifespan of Caenorhabditis elegans. Genetics 141: 1399-1406.

56. Leroi AM, Bartke A, De Benedictis G, Franceschi C, Gartner A, et al. (2005) What evidence is there for the existence of individual genes with antagonistic pleiotropic effects? Mech Ageing Dev 126: 421-429.

57. Ungewitter E, Scrable H (2009) Antagonistic pleiotropy and p53. Mech Ageing Dev 130: 10-17.

58. Hamilton WD (1966) The moulding of senescence by natural selection. J Theor Biol 12: 12-45.

59. Medawar PB (1946) Old age and natural death. Modern Quarterly 1: 30-56.

60. Medawar PB (1952) An unsolved problem of biology. London: Lewis HK.

61. Rose MR (1991) Evolutionary biology of aging. Oxford: Oxford University Press.

62. Lee AK, Cockburn A (1985) Evolutionary ecology of marsupials. Oxford: Oxford University Press

63. Oakwood M, Bradley AJ, Cockburn A (2001) Semelparity in a large marsupial. Proc Biol Sci 268: 407-411.

64. Crespi BJ, Teo R (2002) Comparative phylogenetic analysis of the evolution of semelparity and life history in salmonid fishes. Evolution 56: 1008-1020.

65. Hautekèete N, Piquot Y, Van Dijk H (2001) Investment in survival and reproduction along a semelparity-iteroparity gradient in the Beta species complex. J Evolutionary Biology 14: 795-804.

66. Austad SN (1993) Retarded senescence in an insular population of Virginia Opossums (Didelphis-Virginiana). J Zoology 229: 695-708. 
67. Holmes DJ, Austad SN (1994) Fly now, die later - life-history correlates of gliding and flying in mammals. J Mammal 75: 224-226.

68. Reznick DN, Bryant MJ, Roff D, Ghalambor CK, Ghalambor DE (2004) Effect of extrinsic mortality on the evolution of senescence in guppies. Nature 431: 1095-1099.

69. Abrams PA (1993) Does increased mortality favor the evolution of more rapid senescence? Evolution 47: 877-887.

70. Mitteldorf J, Pepper JW (2007) How can evolutionary theory accommodate recent empirical results on organismal senescence? Theory Biosci 126: 3-8.

71. Leroi AM, Chippindale AK, Rose MR (1994) Long-term laboratory evolution of a genetic life-history trade-off in Drosophila melanogaster. 1. The role of genotype-by-environment interaction. Evolution 48: 1244-1257.

72. Anderson JL, Reynolds RM, Morran LT, Tolman-Thompson J, Phillips PC (2011) Experimental evolution reveals antagonistic pleiotropy in reproductive timing but not life span in Caenorhabditis elegans. J Gerontol A Biol Sci Med Sci 66: 1300-1308

73. Stearns SC (1992) The Evolution of Life Histories. Oxford University Press: Oxford.

74. Mitteldorf J (2004) Ageing selected for its own sake. Evolutionary Ecology Research 6: 937-953.

75. Roff DA, Fairbairn DJ (2007) The evolution of trade-offs: where are we? J Evol Biol 20: 433-447.

76. Libertini G (1988) An adaptive theory of increasing mortality with increasing chronological age in populations in the wild. J Theor Biol 132: 145-162.

77. Libertini G (2006) Evolutionary explanations of the "actuarial senescence in the wild" and of the "state of senility". ScientificWorldJournal 6: 1086-1108.

78. Bourke AF (2007) Kin selection and the evolutionary theory of aging. Annual Review of Ecology, Evolution, and Systematics 38: 103-128.

79. Dickhoff WW (1989) Salmonids and annual fishes: death after sex. In Development, Maturation, and Senescence of Neuroendocrine Systems: A Comparative Approach (ed. M. P. Schreibman\& C. G. Scanes) New York: Academic Press 253-266.

80. Foster RB (1977) Tachigaliaversicolor is a suicidal neotropical tree. Nature 268 624-626.

81. Mitteldorf J (2006) Chaotic population dynamics and the evolution of ageing. Evolutionary Ecology Research 8: 561-574.

82. Chitty D (1996) Do lemmings commit suicide? Beautiful hypotheses and ugly facts. New York: Oxford University Press.

83. McAllister MK, Roitberg BD (1987) Adaptive suicidal behavior in pea aphids. Nature 328: 797-799.

84. McAllister MK, Roitberg BD, Laurence WK (1990) Adaptive suicide in pea aphids: decisions are cost sensitive. Animal Behaviour 40: 167-175

85. Andrade MC (1996) Sexual selection for male sacrifice in the Australian redback spider. Science 271: 70-72.

86. Miller JA (2007) Repeated evolution of male sacrifice behavior in spiders correlated with genital mutilation. Evolution 61: 1301-1315.

87. Foellmer MW, Fairbairn DJ (2003) Spontaneous male death during copulation in an orb-weaving spider. Proc Biol Sci 270 Suppl 2: S183-185.

88. Andrade M (2003) Risky mate search and male self-sacrifice in redback spiders. Behavioral Ecology 14: 531-538.

89. Winston ML (1987) The biology of the honey bee. Cambridge: Harvard University Press.

90. Rueppell O, Hayworth MK, Ross NP (2010) Altruistic self-removal of healthcompromised honey bee workers from their hive. J Evol Biol 23: 1538-1546.

91. Bourke AF, Franks NR (1995) Levels-of-selection theory, gene selectionism, and insect societies. In Social evolution in ants (ed. A. F. G. Bourke \& N. R. Franks) Princeton NJ: Princeton University Press: 39-68.

92. Keeling PJ, Burger G, Durnford DG, Lang BF, Lee RW, et al. (2005) The tree of eukaryotes. Trends Ecol Evol 20: 670-676.

93. Lewis K (2000) Programmed death in bacteria. Microbiol Mol Biol Rev 64: 503514
94. Aravind L, Dixit VM, Koonin EV (1999) The domains of death: evolution of the apoptosis machinery. Trends Biochem Sci 24: 47-53.

95. Gordeeva AV, Labas YA, Zvyagilskaya RA (2004) Apoptosis in unicellular organisms: mechanisms and evolution. Biochemistry (Mosc) 69: 1055-1066.

96. Tan KS, Nasirudeen AM (2005) Protozoan programmed cell death--insights from Blastocystis deathstyles. Trends Parasitol 21: 547-550.

97. Delgado M, Anderson P, Garcia-Salcedo JA, Caro M, Gonzalez-Rey E (2009) Neuropeptides kill African trypanosomes by targeting intracellular compartments and inducing autophagic-like cell death. Cell Death Differ 16: 406-416.

98. Giusti C, Tresse E, Luciani MF, Golstein P (2009) Autophagic cell death: analysis in Dictyostelium. Biochim Biophys Acta 1793: 1422-1431.

99. Patton TG, Rice KC, Foster MK, Bayles KW (2005) The Staphylococcus aureus cidC gene encodes a pyruvate oxidase that affects acetate metabolism and cell death in stationary phase. Mol Microbiol 56: 1664-1674.

100. Mai-Prochnow A, Lucas-Elio P, Egan S, Thomas T, Webb JS, et al. (2008) Hydrogen peroxide linked to lysine oxidase activity facilitates biofilm differentiation and dispersal in several gram-negative bacteria. J Bacteriol 190: 5493-5501.

101. Fabrizio P, Longo VD (2008) Chronological aging-induced apoptosis in yeast. Biochim Biophys Acta 1783: 1280-1285.

102. Hamann A, Brust D, Osiewacz HD (2008) Apoptosis pathways in fungal growth, development and ageing. Trends Microbiol 16: 276-283.

103. Sharon A, Finkelstein A, Shlezinger N, Hatam I (2009) Fungal apoptosis: function, genes and gene function. FEMS Microbiol Rev 33: 833-854.

104. Al-Olayan EM, Williams GT, Hurd H (2002) Apoptosis in the malaria protozoan, Plasmodium berghei: a possible mechanism for limiting intensity of infection in the mosquito. Int J Parasitol 32: 1133-1143.

105. Mariante RM, Vancini RG, Benchimol M (2006) Cell death in trichomonads: new insights. Histochem Cell Biol 125: 545-556.

106. Lee N, Bertholet S, Debrabant A, Muller J, Duncan R, et al. (2002) Programmed cell death in the unicellular protozoan parasite Leishmania. Cell Death Differ 9: 53-64

107. Welburn SC, Dale C, Ellis D, Beecroft R, Pearson TW (1996) Apoptosis in procyclic Trypanosoma brucei rhodesiense in vitro. Cell Death Differ 3: 229 236.

108. Welburn SC, Lillico S, Murphy NB (1999) Programmed cell death in procyclic form Trypanosoma brucei rhodesiense --identification of differentially expressed genes during con A induced death. Mem Inst Oswaldo Cruz 94: 229-234.

109. Häussler S, Becker T (2008) The pseudomonas quinolone signal (PQS) balances life and death in Pseudomonas aeruginosa populations. PLoS Pathog 4: e1000166.

110. Heurlier K, Dénervaud V, Haenni M, Guy L, Krishnapillai V, et al. (2005) Quorum-sensing-negative (lasR) mutants of Pseudomonas aeruginosa avoid cell lysis and death. J Bacteriol 187: 4875-4883.

111. Frangeul L, Quillardet P, Castets AM, Humbert JF, Matthijs HC, et al. (2008) Highly plastic genome of Microcystis aeruginosa PCC 7806, a ubiquitous toxic freshwater cyanobacterium. BMC Genomics 9: 274

112. Ross C, Santiago-Vázquez L, Paul V (2006) Toxin release in response to oxidative stress and programmed cell death in the cyanobacterium Microcystis aeruginosa. Aquat Toxicol 78: 66-73

113. Sigee D, Selwyn A, Gallois P, Dean A (2007) Patterns of cell death in freshwater colonial cyanobacteria during the late summer bloom. Phycologia 46: 284-292.

114. Mai-Prochnow A, Webb JS, Ferrari BC, Kjelleberg S (2006) Ecological advantages of autolysis during the development and dispersal of Pseudoalteromonas tunicata biofilms. Appl Environ Microbiol 72: 5414-5420.

115. Allesen-Holm M, Barken KB, Yang L, Klausen M, Webb JS, et al. (2006) A characterization of DNA release in Pseudomonas aeruginosa cultures and biofilms. Mol Microbiol 59: 1114-1128.

116. Whitchurch CB, Tolker-Nielsen T, Ragas PC, Mattick JS (2002) Extracellular DNA required for bacterial biofilm formation. Science 295: 1487

117. Kim Y, Wang X, Ma Q, Zhang XS, Wood TK (2009) Toxin-antitoxin systems in Escherichia coli influence biofilm formation through YjgK (TabA) and fimbriae. 
J Bacteriol 191: 1258-1267.

118. Nariya $\mathrm{H}$, Inouye $\mathrm{M}(2008) \mathrm{MazF}$, an mRNA interferase, mediates programmed cell death during multicellular Myxococcus development. Cell 132: 55-66.

119. Chao L, Levin BR (1981) Structured habitats and the evolution of anticompetitor toxins in bacteria. Proc Natl Acad Sci U S A 78: 6324-6328.

120. Le Gac M, Doebeli M (2010) Environmental viscosity does not affect the evolution of cooperation during experimental evolution of colicigenic bacteria. Evolution 64: 522-533

121. Buss LW (1982) Somatic cell parasitism and the evolution of somatic tissue compatibility. Proc Natl Acad Sci U S A 79: 5337-5341.

122. Fröhlich KU, Madeo F (2000) Apoptosis in yeast--a monocellular organism exhibits altruistic behaviour. FEBS Lett 473: 6-9.

123. Váchová L, Palková Z (2005) Physiological regulation of yeast cell death in multicellular colonies is triggered by ammonia. J Cell Biol 169: 711-717.

124. Frank SA (1996) Models of parasite virulence. Q Rev Biol 71: 37-78.

125. Kerr B, Neuhauser C, Bohannan BJ, Dean AM (2006) Local migration promotes competitive restraint in a host-pathogen 'tragedy of the commons'. Nature 442: 75-78.

126. van Zandbergen G, Bollinger A, Wenzel A, Kamhawi S, Voll R, et al. (2006) Leishmania disease development depends on the presence of apoptotic promastigotes in the virulent inoculum. Proceedings of the National Academy of Sciences of the USA 103: 13837-13842.

127. Adamec F, Kaftan D, Nedbal L (2005) Stress-induced filament fragmentation of Calothrixelenkinii (Cyanobacteria) is facilitated by death of high-fluorescence cells. J Phycology 41: 835-839.

128. Berman-Frank I, Bidle K, Haramaty L, Falkowski P (2004) The demise of the marine cyanobacterium, Trichodesmium spp., via an autocatalyzed cell death pathway. Limnology And Oceanography 49: 997-1005.

129. Kolodkin-Gal I, Engelberg-Kulka H (2008) The extracellular death factor: physiological and genetic factors influencing its production and response in Escherichia coli. J Bacteriol 190: 3169-3175.

130. Engelberg-Kulka H, Amitai S, Kolodkin-Gal I, Hazan R (2006) Bacterial programmed cell death and multicellular behavior in bacteria. PLoS Genet 2: e135.
131. Pandey DP, Gerdes K (2005) Toxin-antitoxin loci are highly abundant in freeliving but lost from host-associated prokaryotes. Nucleic Acids Res 33: 966 976.

132. Brunskill EW, Bayles KW (1996) Identification of LytSR-regulated genes from Staphylococcus aureus. J Bacteriol 178: 5810-5812.

133. Bayles KW (2007) The biological role of death and lysis in biofilm development Nat Rev Microbiol 5: 721-726.

134.Cornillon S, Foa C, Davoust J, Buonavista N, Gross JD, et al. (1994) Programmed cell death in Dictyostelium. J Cell Sci $107: 2691-2704$.

135. Tatischeff I, Petit PX, Grodet A, Tissier JP, Duband-Goulet I, et al. (2001) Inhibition of multicellular development switches cell death of Dictyostelium discoideum towards mammalian-like unicellular apoptosis. Eur J Cell Biol 80: 428-441.

136. Burt A, Trivers R (2006) Genes in conflict: The biology of selfish genetic elements. Cambridge MA: Harvard University Press.

137. Skinner SW (1985) Son-killer: a third extrachromosomal factor affecting the sex ratio in the parasitoid wasp, Nasonia (=Mormoniella) vitripennis. Genetics 109: $745-759$

138. Koren A (2006) Is Saccharomyces cerevisiae apoptotic cell death associated with gene transfer? IUBMB Life 58: 203-207.

139. Engelberg-Kulka H, Glaser G (1999) Addiction modules and programmed cell death and antideath in bacterial cultures. Annu Rev Microbiol 53: 43-70.

140. Young R (2002) Bacteriophage holins: deadly diversity. J Mol Microbio Biotechnol 4: 21-36.

141. Wilson DS, Wilson EO (2007) Rethinking the theoretical foundation of sociobiology. Q Rev Biol 82: 327-348.

142. Leadsham JE, Gourlay CW (2008) Cytoskeletal induced apoptosis in yeast Biochim Biophys Acta 1783: 1406-1412.

143. Severin FF, Meer MV, Smirnova EA, Knorre DA, Skulachev VP (2008) Natural causes of programmed death of yeast Saccharomyces cerevisiae. Biochim Biophys Acta 1783: 1350-1353.

144.Webb JS, Givskov M, Kjelleberg S (2003) Bacterial biofilms: prokaryotic adventures in multicellularity. Curr Opin Microbiol 6: 578-585. 